\title{
8
}

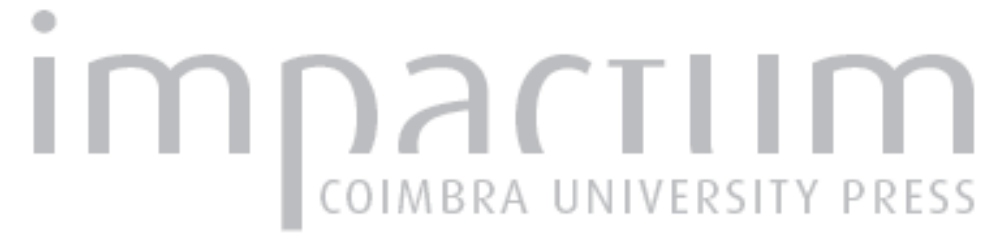

\section{Guido Batelli e a poesia portuguesa}

Autor(es): $\quad$ Simões, Manuel G.

Publicado por: Imprensa da Universidade de Coimbra

URL persistente:

URl:http://hdl.handle.net/10316.2/42530

DOI:

DOI:https://doi.org/10.14195/0870-8584_5_16

Accessed : $\quad$ 26-Apr-2023 13:42:33

A navegação consulta e descarregamento dos títulos inseridos nas Bibliotecas Digitais UC Digitalis, UC Pombalina e UC Impactum, pressupõem a aceitação plena e sem reservas dos Termos e Condições de Uso destas Bibliotecas Digitais, disponíveis em https://digitalis.uc.pt/pt-pt/termos.

Conforme exposto nos referidos Termos e Condições de Uso, o descarregamento de títulos de acesso restrito requer uma licença válida de autorização devendo o utilizador aceder ao(s) documento(s) a partir de um endereço de IP da instituição detentora da supramencionada licença.

Ao utilizador é apenas permitido o descarregamento para uso pessoal, pelo que o emprego do(s) título(s) descarregado(s) para outro fim, designadamente comercial, carece de autorização do respetivo autor ou editor da obra.

Na medida em que todas as obras da UC Digitalis se encontram protegidas pelo Código do Direito de Autor e Direitos Conexos e demais legislação aplicável, toda a cópia, parcial ou total, deste documento, nos casos em que é legalmente admitida, deverá conter ou fazer-se acompanhar por este aviso.

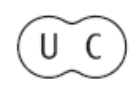




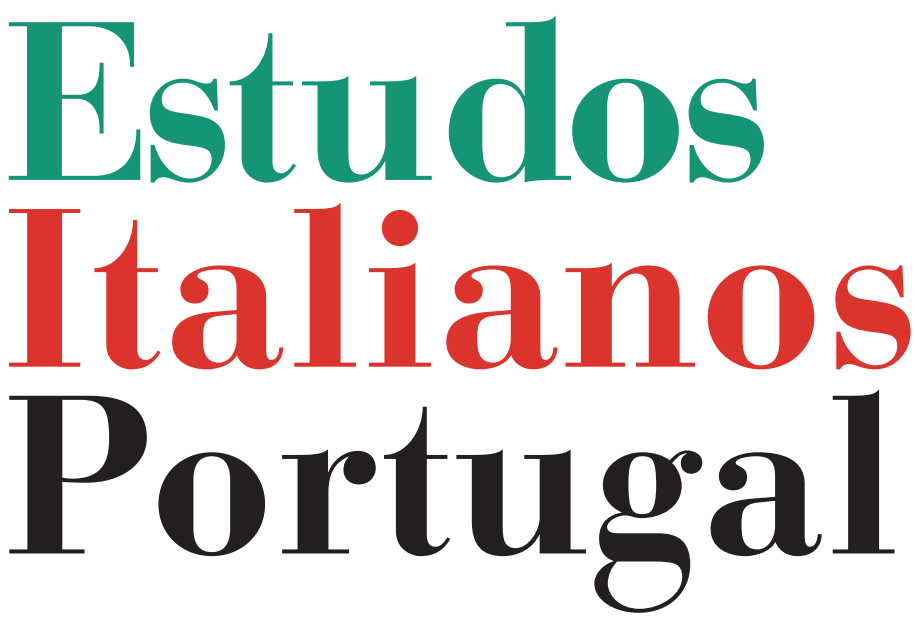

Instituto

Italiano

de Cultura

de Lisboa

Nova Série

$\mathrm{N}^{\mathbf{0}} 5$ 


\title{
GUIDO BATELLI E A POESIA PORTUGUESA
}

\author{
Manuel G. Simões ${ }^{\star}$
}

\section{INTRODUÇÃO}

Este poeta e ensaísta, estudioso da cultura italiana e responsável pela divulgação, em Itália, dos poetas portugueses dos finais do século XIX e inícios do século XX, nasceu em Sarzana/Génova, de família parmigiana, em 24 de Setembro de 1869 e morreu em Florença em 1955. Frequentou as universidades de Parma, onde se licenciou em Direito, e de Florença, concluindo aqui o curso de Filosofia. Cedo se interessou pelos clássicos italianos, se considerarmos as monografias que dedicou a Pietro Aretino (1914 e 1923), a Niccolò Tommaseo (1916, 1919 e 1920), a Marino (1926) ou aos Fioretti di San Francesco (1929), entre muitos outros exemplos.

Tem-se dito que por voltas de 1930 foi Leitor de Língua Italiana na Faculdade de Letras da Universidade de Coimbra, mas, de acordo com Livia Apa, e com base em informações fornecidas pela neta de Battelli, em 1989, este "arriva in Portogallo nel 1930 e ci resta quattro anni" ${ }^{1}$. Todavia o

* Manuel G. Simões é professor jubilado de literatura portuguesa e brasileira da Universidade Ca’ Foscari de Veneza. Poeta e ensaísta. Pertence à redacção da revista Rassegna Iberistica, de que foi um dos fundadores em 1978.

1 Livia Apa, "Guido Battelli e la cultura portoghese", in L 'apporto italiano alla tradizione degli studi ispanici. Atti del congresso "Nel ricordo di Carmelo Samonà", Napoli 30 e 31 gennaio, 1 febbraio 1992.Roma, Istituto Cervantes, 1993, pp. 171-172. Segundo parece, terá sido o genro, Guido Vitaletti, que exerceu 
seu contacto profundo com a cidade do Mondego é decerto precedente, dado que a publicação do seu livro de poemas Coimbra (Lanciano, G. Carabba, 1928), com duas composições escritas já em 1927, revela uma empatia sentimental com os lugares e os grandes mitos da cidade, tal como deixa transparecer a epígrafe de António Nobre: "Oh Coimbra sem par, flor das cidades”. São, de facto, significativos, a este respeito, os temas escolhidos por Guido Battelli e que testemunham a grande intimidade com o espírito do lugar, longe de uma mera visão epidérmica de eventual viajante, mesmo com interesses culturais: "Primavera a Coimbra" (onde se evoca o choupal); "Tramonto d'estate" (pretexto para inserir um quadro que envolve a Sé Velha); "Plaza do Commercio" [sic]; "Quebra-costas", com nota explicativa sobre a sua morfologia no tecido urbano; "Cindazunda"; "Santa Cruz", "Rua do Norte"; "Choupal"; "Arcobaleno"; "Il grifo de Lorvão", texto em prosa datado de Agosto de 1927; e "Voce di Dio sulle acque", reflexão/oração da viagem por mar, a bordo do "Presidente Wilson" (22-7-1927), de Nápoles para Lisboa.

Tudo indica que a sua chegada a Coimbra foi, portanto, precedente a 1930, se considerarmos até a publicação, logo em 1929, de alguns estudos sobre relações culturais luso-italianas, como o que contemplava o naturalista italiano Domenico Vandelli (Pádua, 1735-Lisboa, 1816), professor de História Natural na Univ. de Coimbra (Domenico Vandelli e il giardino botanico di Coimbra, Coimbra, Coimbra Editora, 1929) ou outros que, já então, demonstravam o conhecimento interrelacional entre as duas culturas: Il Sansovino in Portogallo (Coimbra, Coimbra Editora, 1929), mais tarde republicado com o título Sansovino Andrea e l' arte italiana della rinascenza in Portogallo (Firenze, Lib.Seeber, 1936), com 24 reproduções de fotografias inéditas; Il terremoto di Lisbona nelle memorie degli influenciar a transferência de Battelli de Florença para Coimbra. Cf. ib., p. 171. 
scrittori italiani contemporanei (Coimbra, Coimbra Editora, 1929); e Note critiche di storia dell'arte italiana in Portogallo (Coimbra, Coimbra Editora, 1929). A circunstância de esta editora lhe publicar quatro estudos no mesmo ano de 1929 parece atestar a implantação sólida do Autor na cidade, onde certamente já era bastante conhecido ${ }^{2}$. E, de facto, graças a estudos recentes, estamos hoje em condições de contrariar a memória esbatida da neta, dado que foi possível averiguar, com toda a certeza, que o início da colaboração de Guido Battelli com a Faculdade de Letras de Coimbra remonta a 1928, ao assumir funções docentes, como professor de italiano, no Curso de Férias daquele $a_{n}^{3}$ e cuja cerimónia de encerramento se caracterizou pela condecoração de Battelli e de Vitaletti com a ordem de Santiago da Espada ${ }^{4}$. Sabe-se ainda que regeu a cadeira de História da literatura italiana no ano lectivo de 1929-1930, contratado como professor auxiliar, segundo consta do respectivo "Livro dos Sumários" da FLUC5.

A sua passagem por Coimbra se, por um lado, deve ter contribuído para o conhecimento sistemático da literatura portuguesa da época, sobretudo da poesia, por outro não terá sido pacífica e isenta de litígios e de intrigas de vário tipo vindas do corpo académico, provavelmente pela forma

2 A estes estudos, Guido Battelli haveria de acrescentar outros trabalhos sobre as relações culturais entre Portugal e a Itália, tais como:'”Livros de Cordel' posseduti dalla Biblioteca Nazionale di Firenze", La Bibliofilia, Firenze 1939, 41, pp. 267-276; Relazioni tra il Portogallo e la Toscana in occasione della impresa d'Africa del re don Sebastiano (1578) (s.1., s/d, 1941 ?); L 'albo dei disegni di Francisco d'Ollanda (Roma 1942).

3 Cf. Rita Marnoto, "O ensino da língua e da literatura italianas na Universidade de Coimbra", in Para uma história das línguas e literaturas estrangeiras em Portugal: das origens à actualidade, Actas do I Colóquio da APHELLE, Univ. de Aveiro, 23 e 24 de Novembro de 2000, Dafundo, APHELLE, p. 100.

${ }^{4}$ Cf. Jorge Pais de Sousa, Uma Biblioteca Fascista em Portugal, Coimbra, Imprensa da Universidade de Coimbra, 2007, pp. 18-19.

5 Agradeço esta informação à Prof. e amiga Rita Marnoto, a cuja sensibilidade fico a dever estas e outras informações. 
como quis evidenciar-se no conhecido contacto que acabou por estabelecer com a poetisa Florbela Espanca, e de que se falará mais adiante. Diz-se, até, que Battelli decidiu abandonar Coimbra após a intervenção de Eugénio de Castro, director da "Sala Italiana", atitude que está na base do profundo ressentimento que transparece na crítica que dedica ao autor de Oaristos. De facto, se na introdução que escreve para Lirici Portoghesi Moderni, primeira antologia de poesia portuguesa moderna publicada em Itália, introdução datada de Coimbra, Novembro de 1928, a poesia de Eugénio de Castro é caracterizada por "raffinatezze verbali, le cesellatture sapienti, lo splendore delle immagini", , passados que foram vinte anos e já depois da morte do poeta, a leitura de Guido Battelli parece assumir aspectos de ajuste de contas, não sem evidentes laivos de crueldade. Com a intenção de enaltecer a poética de Florbela e revelando um conhecimento limitado - talvez condicionado por interesses derivados da sua própria formação intelectual e posição ideológica em consonância com o fascismo italiano - da evolução da poesia portuguesa, atribuindo-lhe um processo degenerativo, responsabiliza Eugénio de Castro por esta degeneração, dando como exemplo um segmento textual em que, segundo ele, o poeta chega até a "cantare un merlo imbalsamato sotto una campana di vetro" ". E nas notas ao texto, o juízo crítico é ainda mais cáustico e radical: "Se noi esaminiamo le altre produzioni del De Castro [para além de Oaristos], troviamo in tutte lo stesso artificio, la stessa falsità, la stessa assenza di

6 Lirici Portoghesi Moderni. Tradotti da Guido Battelli, Lanciano, G. Carabba, 1929, pp. IX-X.

7 Florbela Espanca. Ricordo di Guido Battelli, Firenze, Il Cenacolo, 1950, p. 6. Na verdade, já no "estudo crítico" que escreveu como introdução a Juvenilia, de Florbela Espanca, datado de Coimbra, Outubro de 1931, e abordando o problema da sinceridade em arte, apresenta como exemplo a "Canção do Passarinho reembalsamado", de E. de Castro, acusando-o de superficialidade sem emoção. Cf. a reedição desta obra, Sintra, Colares editores, 2005, pp. 49-51. 
un pensiero originale, Sagramor è una ridicola caricatura del Faust goethiano [...] Sagramor è un imbecille annoiato di tutto, che non si sa cosa cerchi e che cosa voglia".

\section{O TRADUTOR DE POESIA}

Da vasta bibliografia de Guido Battelli, ressalta a atenção especial dedicada à poesia portuguesa se considerarmos a grande divulgação, feita em Itália, através de estudos e traduções ${ }^{9}$. A primeira antologia é a já referida Lirici Portoghesi Moderni (1929) publicada na colecção "Scrittori Italiani e Stranieri" de G. Carabba e que engloba 24 poetas, desde Almeida Garrett a Carlos Lobo de Oliveira, então jovem promessa, hoje desconhecido - e com um apêndice dedicado ao poeta galego Avelino de Gomez Ledo -, passando por A. Herculano, João de Deus (escrito Giovanni de Deus), Guerra Junqueiro, Antero de Quental, António Nobre, Gomes Leal, Eugénio de Castro, Afonso Lopes Vieira e outros menos importantes. É uma antologia que pretende colmatar uma injusta lacuna que se foi produzindo em Itália relativamente à literatura portuguesa contemporânea.

A escolha é feita de acordo com o temperamento e sensibilidade do tradutor, o qual produz uma nota explicativa sobre os critérios tradutológicos. Ultrapassando a antiga questão da tradução fidelíssima em prosa, palavra por palavra, sacrificando o resto (ritmo, harmonia, por exemplo) ou tentar transferir tudo isto numa versão poética, é claro que opta pela última: "Dirò soltanto che leggendo i poeti portoghesi mi sono sentito risuonare nell'anima il loro canto con lo stesso

8 Ib., nota 2, p. 19.

9 Simultaneamente Battelli também difundiu a poesia italiana em Portugal. Veja-se Líricos Italianos Modernos, in Biblos, Coimbra, Nov./Dez. 1930, breve antologia que inclui poemas de Manzoni, Leopardi, Carducci, Pascoli, D’ Annunzio e Ada Negri. 
loro ritmo e spesso con le stesse loro parole e le stesse rime, e come ho sentito ho scritto" ("Avvertenza”, p. II).

O método parece basear-se na intuição e no sentimento pessoal de um intérprete que considerava, à partida, a poesia portuguesa como “quella che piú s' avvicina alla nostra” (ib., p. II). Daí que Battelli tenha frequentemente caído na tentação de aproximar os poetas portugueses dos grandes autores italianos, chegando à afirmação de que, excluindo Camões, a literatura portuguesa dos séculos passados é uma imitação, porventura feliz, primeiro de Petrarca, depois dos Humanistas e finalmente dos Árcades italianos ("Introduzione", p. IV). Ainda nas páginas de introdução à antologia, por exemplo, argumenta que Herculano "ricorda il nostro Muratori”, e, por se ter retirado para a solidão agreste, "ricorda il Manzoni" (p. V); que A. F. de Castilho, pela inspiração religiosa, se pode comparar a Manzoni (p. 13); ou que Soares de Passos recorda o italiano Prati (p. 16). Antero de Quental, das Odes Modernas, é assimilado a Carducci ${ }^{10}$, enquanto o dos Sonetos se aproxima de Leopardi ("Introduzione", p. VII). Noutros lugares continua G. Battelli este trabalho de aproximação: Leopardi está também no horizonte de António Nobre ${ }^{11}$, Gomes Leal no de Emilio Praga ${ }^{12}$ e Teixeira de Pascoaes no de Ugo Foscolo e ainda no de Leopardi ${ }^{13}$.

Depois de Lirici Portoghesi Moderni, Battelli volta a divulgar a poesia portuguesa em Itália com a antologia de António Nobre, já referida, na qual insere uma dedicatória "alla città di Porto cara ad ogni cuore italiano per la memoria di re Carlo Alberto" (p. 5). Trata-se de uma escolha criteriosa

10 Cf. G. Battelli, "Le Saudades paganas di Antero de Quental e la poesia di Giosuè Carducci”, Biblos, 6, 1930.

11 Antonio Nobre, Liriche. Tradotte da Guido Battelli, Firenze, Libreria Seeber, 1933.

12 Antonio Gomes Leal, Liriche. Tradotte da Guido Batteli, Firenze, Libreria Seeber, 1933.

13 G. Battelli, Teixeira de Pascoaes, Coimbra, 1953. 
e com uma organização textual que implica a vida e morte do poeta, balizadas pelas composições "Antonio", primeiro poema e "L'albergo dei morti" com que se fecha a antologia. Na "Introdução", datada de "Firenze, luglio 1932", após algumas considerações pertinentes destinadas a contextualizar o poeta, reitera o tradutor o essencial do seu critério tradutológico, já posto em prática e consolidado: "Ho cercato di mantenermi fedele non solo allo spirito e al contenuto, ma anche alla forma, al ritmo, all'armonia del verso" (p. 10). E no mesmo ano de 1933, publica Battelli, com o mesmo editor de Florença (Libreria Seeber) a antologia de António Gomes Leal, Liriche, também anteriormente citada. Todos os poemas, com excepção do último ("Vecchio palazzo" do volume Fim do Mundo) são extraídos de Claridades do Sul (2. ed. revista e aumentada, 1901) e traduzidos com o mesmo critério, procurando "conservare il ritmo e il metro dell' originale [...] anche le rime" (p. 8). Aliás, como já tinha advertido na introdução a Lirici Portoghesi Moderni, também aqui reitera a opinião de que a tradução da poesia portuguesa não apresenta sérias dificuldades, isto porque é sua convicção que, entre as línguas neo-latinas, não há nenhuma que se aproxime da italiana quanto a portuguesa. E vai até mais longe, ao afirmar que nenhum país da Europa recorda tanto a Itália quanto Portugal ("Introduzione", datada de Coimbra, 4 de Set. $^{\circ}$ 1930/Firenze, 2 de Jan. ${ }^{\circ}$ 1933, pp. 8-9).

Passada esta fase de intensa actividade como tradutor da poesia portuguesa, e deixando de parte a atenção particular que continua a dedicar à poesia de Florbela Espanca, Guido Battelli só reaparece como divulgador, em Itália, de textos poéticos portugueses, com uma breve monografia sobre Guerra Junqueiro, já de 1951, um ano depois do centenário do nascimento do Poeta ${ }^{14}$. Pode dizer-se que, nessa altura,

14 G. Battelli, "Abilio Guerra-Junqueiro", in Letterature Moderne, 2, 6, nov.-dic. 1951, pp. 676-679. 
o discurso de Battelli está, no mínimo, desactualizado, sem nunca ter aflorado, pelo menos a título de informação, o impacto dos movimentos modernista, presencista ou neo-realista e continuando a privilegiar os poetas dos finais do século XIX, como João de Deus, que considera o poeta mais amado do povo, ou Guerra Junqueiro. E visto ser o último o poeta que aqui quer homenagear, insere, como amostra do verbo junqueireano, dois poemas já propostos em Lirici Portoghesi Moderni, agora numa tradução com algumas variantes, um poema de Os Simples, mais dois fragmentos da "Oração à Luz" e da "Oração ao pão". Refira-se, porém que, em 1951, a idade de Guido Battelli, já avançada, não lhe permitiria um esforço de informação, mas os seus interesses, no âmbito da poesia portuguesa, nunca contemplaram as vanguardas poéticas do século XX; a sua predilecção recaiu sempre sobre autores de veia intimista, neo-romântica e, em especial, sobre a poesia com uma forte componente religiosa ou mística.

\section{O caso Florbela Espanca}

É este último ingrediente o factor que certamente determinou a grande sedução pela poética de Florbela Espanca, uma empatia que a levou a confiar-lhe o manuscrito de Charneca em Flor, em fase de revisão de provas no momento da morte da poetisa (8-12-1930), volume que só sairá postumamente no ano seguinte ${ }^{15}$. O apreço imediato de Battelli por uma poesia que encontrava ecos profundos na sua sensibilidade crítica explica a determinação de divulgá-la imediatamente

15 De facto é Battelli quem se ocupa da publicação de Charneca em Flor (Coimbra, Liv. Gonçalves, 1931) e também de outras obras de Florbela: Livro de Mágoas e de Soror Saudade, reedição de dois volumes publicados precedentemente em 1919 e em 1923 (Coimbra, Liv. Gonçalves, 1931), Juvenilia (Coimbra, Liv. Gonçalves, 1931), esta acompanhada de um "estudo crítico". 
em Itália, com a tradução de oito sonetos do Livro de Mágoas que publica na revista Rassegna Nazionale (Agosto-Setembro de 1930), de que Florbela Espanca diz já ter recebido um exemplar na sua carta de 17-11-1930 ${ }^{16}$.

Este interesse acaba por aproximar os dois interlocutores, sobretudo a partir das lamentações da poetisa relativamente à apatia dos editores pelo seu novo livro, Charneca em Flor, não obstante o êxito, mais auspiciado que verdadeiro, dos dois primeiros, "esgotados [...] em poucos meses" (carta de 27-6-1930) ${ }^{17}$, e da consequente disponibilidade de Battelli para lhe encontrar um editor, como veio a acontecer. Foi uma adesão certamente não desinteressada e, de qualquer modo, não isenta de comentários acintosos, de intrigas de bastidores, ao ponto de suscitar uma grande animosidade, que o tempo ainda não atenuou.

Agustina Bessa Luís, por exemplo, na sua biografia de Florbela Espanca, de 1976, ao falar do amor de Battelli pela poetisa, sentimento mais do que provável mas não provado, a não ser literariamente ${ }^{18}$, produz um discurso que parece excessivo no seu julgamento inflexível e peremptório:

Esse homem desiludido com as letras agarra-se desesperadamente à importância de amar uma mulher rara. Porque ele sabe quanto Bela é extraordinária. A sua infelicidade não o comove talvez; é o seu talento que ele cobiça como riqueza que ele não possui, que o ensinaram a venerar; e ao serviço de que ele anda

16 Cartas de Florbela Espanca a Dona Júlia Alves e a Guido Battelli, Coimbra, Liv. Gonçalves Editora, 1931, p. 36.

17 Ib., p. 22.

18 Veja-se o poema de Battelli, intitulado "Florbela Espanca", datado de Agosto de 1930: "S'ogni terreno amor, di', non ti basta,/deh, perchè I'occhio, non sollevi al Ciel,/perchè ricusi di veder la fiamma/ch'arde nascosta dentro il nostro vel? [...] Ch'amo il tuo spirito, ch'io ben so immortale,/ch'amo di te quel che morir non può,/ch'amo del canto l'ala tua superba,/e il tuo dolore, ch'io lenir non so?" (in Juvenilia, ed. cit., pp.55-57). 
- professor errante e sem sucesso, sujeito às intrigas dos colegas, sem fortuna, sem grandeza, a não ser a sua colecção de fotografias de Veneza. Oferece Veneza a Florbela, na volta do correio, com uma magnificência de doge ${ }^{19}$.

É um comentário a que faltam, no mínimo, argumentos sólidos que a autora talvez dê como adquiridos, quando se refere ao "professor errante e sem sucesso", com uma ponta de fantasia de que a notável ficcionista não consegue desprender-se, mesmo quando o discurso requereria maior objectividade. Mas que sabe Agustina do itinerário intelectual de Guido Battelli? Para alguém que nos legou mais de centena e meia de títulos, desde estudos dos clássicos italianos a volumes de traduções de poesia portuguesa, passando pelas relações culturais entre a Itália e Portugal, não se pode dizer que se trata de uma figura mesquinha e sem grandeza. Merece ser censurado mas seria necessária a motivação explícita e, já agora, mais serena. E, logo a seguir, Agustina volta a referir-se a Battelli de modo pouco lisonjeiro e nem sempre pertinente:

"[Florbela] tem a agradecer-lhe o que resultou dum acto não muito nobre: que Battelli legasse as suas cartas à Biblioteca de Évora, onde as encontrei outra vez lacradas, depois de consultadas pelo Dr. Celestino David? [...] Ao publicar as cartas de Florbela, Battelli não se comporta de maneira muito honesta; é aleivoso e mal-intencionado. Talvez sofra e queira vingar-se - de Bela, do marido, da Universidade de Coimbra, da velhice, de tudo"20.

Ora não me parece que o legado à Biblioteca de Évora resulte de um "acto não muito nobre", como considera a

19 Agustina Bessa-Luís, Florbela Espanca. Biografia, 4. ${ }^{a}$ ed., Lisboa, Guimarães Editores, 2001, p. 174 (1. ${ }^{\text {e }}$ ed., 1976).

$20 \mathrm{Ib} ., \mathrm{pp} .176-177$. 
ilustre escritora. $\mathrm{Na}$ verdade, que melhor lugar poderia ter sido eleito para conservar a memória da poetisa senão uma biblioteca, para mais prestigiosa e duma cidade onde ela viveu e estudou? Quanto à publicação das cartas, logo em 1931, reconhece-se a insensatez da oportunidade, até por se tratar de uma parte do espólio que não lhe pertencia por direito, embora não subscreva a tese da vingança, visto que no mesmo ano faz publicar em Coimbra, como atrás ficou dito, a obra poética de Florbela, não obstante o reconhecimento de que os estudos que precedem os poemas de Juvenilia ("Florbela Espanca.1894-1930"; "O sentimento da Natureza na poesia de Florbela Espanca"; "A Vida, o Amor e a Morte na poesia de Florbela Espanca"; "O valor da obra poética de Florbela Espanca") se podem ler tendo em consideração a componente narcisista, aspecto que acomuna os dois interlocutores.

Mais consistente e de outro teor é o discurso da conhecida estudiosa Maria Lúcia Dal Farra, a qual explica certas manipulações, de que o professor italiano viria a aproveitar-se, a partir do mistério da morte da poetisa, criado pela própria família: "Há uma maciça mistificação em torno desse acontecimento (família católica, interdição da palavra 'suicídio' na imprensa, receio de falatório), o que não escapa a Battelli"21. De acordo com a estudiosa, este terá engendrado o projecto de promoção da poetisa, tendo em conta o próximo lançamento de Charneca em Flor, cuja edição inaugural continha um "In Memoriam", de Battelli, veiculando a tese da sobreposição completa da biografia à obra ${ }^{22}$. O grande êxito editorial do livro fica a dever-se, em boa parte, a esta leitura, divulgada aliás por Guido Battelli através duma série de textos que consegue publicar na imprensa portuguesa, como

21 Maria Lúcia Dal Farra, "O affaire Florbela Espanca", in Poemas de Florbela Espanca, estudo introdutório, organização e notas de M.L. Dal Farra, 4. ${ }^{a}$ tiragem,

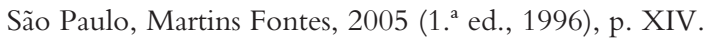

${ }^{22}$ Cf. ib., p. XV. 
um programa bem definido, logo a seguir à morte:"'Florbela Espanca, poetisa alentejana", Diário de Notícias, Lisboa, 14-12-1930; "Florbela Espanca", Correio de Coimbra, em 20-12-1930; "Elegia à morte de Florbela Espanca", Jornal de Notícias, Porto, 21-12-1930; "Charneca em Flor", de novo no Diário de Notícias, Lisboa, 25-1-1931, jornal que alcançou através do correspondente alentejano Celestino David; e "Elegia", Portugal Feminino, Lisboa, 31-1-1931.

Também José Carlos Seabra Pereira, num estudo recente, referindo-se à edição póstuma de Charneca em Flor, assaca responsabilidades ao revisor final da obra, afirmando que há "fundadas razões para considerar que saiu com erros e com alterações de responsabilidade alheia, certamente imputáveis a Guido Battelli" 23 . E quanto às cartas, levianamente publicadas, já a nota "Ao Leitor", subscrita por Júlia Alves e Guido Battelli, esclarece que são apenas um fragmento da correspondência trocada com Florbela Espanca. De facto, a primeira carta publicada e dirigida ao segundo dos destinatários é escrita em Évora, em 27-6-1930, mas depreende-se que há contactos precedentes, que se retoma um diálogo já estabelecido e, com efeito, a primeira tem a data de 18 daquele mês. Mas o que aquela nota não esclarece é o porquê da selecção das cartas e porque é que "retira das cartas trechos que julga indiscretos à sua pessoa, confunde ou extrai datas, interfere nos originais, fabricando, enfim, a seu gosto, interpolações de toda sorte" ${ }^{24}$, criando, deste modo, um equívoco, destinado a perdurar, quanto à relação mecanicista entre a vida e a obra. Neste sentido se pronuncia igualmente Rui Guedes, na "introdução" às Cartas e Diário de Florbela, quando escreve: "Guido Battelli foi ainda mais

23 José Carlos Seabra Pereira, "Nota sobre Charneca em Flor" , in Obras de Florbela Espanca. Obra Poética, vol. I. Livro de Mágoas, Livro de Soror Saudade, Charneca em Flor, introdução e organização de J. C. Seabra Pereira, Lisboa, Ed. Presença, 2009, p. 200.

${ }^{24}$ Maria Lúcia Dal Farra, cit., p. XVII. 
longe ao omitir parágrafos completos, ao montar cartas com parágrafos retirados de outras cartas, ou ao redigir ele próprio parágrafos ou frases que Florbela não escreveu" 25 . $\mathrm{Na}$ verdade, confrontando a transcrição feita por Rui Guedes com o texto publicado por Guido Battelli em 1931, constata-se a eliminação de segmentos textuais, mas não raro dizem respeito a efemérides ou parecem defender certa neurastenia da Autora, como, por exemplo, ao eliminar o exórdio da carta de 27-7-1930, que termina deste modo: "De mim ninguém gosta, de mim nunca ninguém gostou" 26 . Outras vezes percebe-se, mas não se justifica, a "ocultação" por motivos ideológicos que colidiam com a ideologia fascista de Battelli. Escreve Florbela em 12-8-1930:

Exercícios militares, espingardas, couraçados, canções de guerra... que horror![...] "Soror Saudade" iria, devagarinho, em bicos de pés, pedir silêncio em nome dos grandes fantasmas adormecidos. E tenho a certeza que Miguel Ângelo, Galileu e todos os outros me diriam, contentes: fizeste bem, "Soror Saudade", é tão doce o silêncio, tão bom dormir em paz! Só Maquiavel, diplomaticamente, não diria nada, com receio de complicações com Mussolini... ${ }^{27}$

E também se entende por que não transcreve as cartas de 6-11-1930 e de 11 do mesmo mês: não a quer envolver em matéria tão delicada. Na primeira, Florbela lamenta que alguém tenha publicado num jornal grosserias e injustiças que feriam um hóspede tão dedicado ao nosso país; na segunda torna explícito o nome desse "alguém”, Eugénio de Castro, mostrando-se Florbela tão solidária com

25 Florbela Espanca, Cartas e Diário, organização, introdução e notas de Rui Guedes, Venda Nova, Bertrand Editora, 1995, p. 9.

${ }^{26} I b .$, p. 191.

27 Ib., pp. 200-201. 
Battelli a ponto de escrever: "O soneto que me enviou, "Santa Cecília", de Eugénio de Castro, é simplesmente uma patetice" 28 .

O encontro com a poetisa portuguesa, como se vê, marcou profundamente Guido Battelli e o suicídio inesperado, em 8-12-1930, deve-o ter deixado desconcertado, para mais tendo entre mãos as provas revistas de Charneca em Flor, a que se referem as cartas de Florbela de 30-11 e de 5-12 de 1930. Tendo deixado definitivamente Portugal em Janeiro de $1932^{29}$, continua a ocupar-se da divulgação da obra, se atendermos à ampla antologia Versi di Florbela Espanca tradotti dal portoghese da Guido Battelli, curiosamente publicada no Porto em 1934, composta por 28 sonetos, 8 de Livro de Mágoas, 12 de Charneca em Flor e 8 de Reliquiae. Aqui se pode confirmar a sua capacidade de tradutor, como se pode observar pelo último terceto do conhecido soneto "Árvores do Alentejo", que lhe tinha sido dedicado, oferecendo o que se pode chamar uma tradução de autor, seguindo, é claro, a prosódia da época:
Árvores! Não choreis! Olhai e vede:
- Também ando a gritar, morta de sede, pedindo a Deus a ninha gota de água!
[“Alberi, non piangete! Anch'io da dura sete sospinta ne' miei passi erranti, anelo abbeverarmi a le sorgenti!']

No ano seguinte, propõe em Florença uma breve monografia de 10 páginas sobre a poetisa ${ }^{30}$, depois do que só muito mais tarde celebra de novo a sua poesia, pondo-a em contraposição com a de Eugénio de Castro, o qual, não obstante

28 Ib., p. 221.

29 Cf. Maria Lúcia Dal Farra, cit., p. XVII.

${ }^{30}$ Guido Battelli, Florbella Espanca: 1894-1930, Firenze 1935. 
o fluir do tempo, continua a ser o seu grande inimigo ${ }^{31}$. Aqui proclama a sua fidelidade ao discurso poético de Florbela, considerando Charneca em Flor como o mais apaixonado livro de amor da poesia portuguesa sua contemporânea. E recuperando talvez material antigo, publica ainda o ensaio "O Alentejo na poesia de Florbela Espanca" ( $A$ Cidade de Évora, 25-26, 1951), que parece ter sido a última homenagem à mulher e à escritora que o marcou profundamente na sua breve mas intensa passagem por Portugal.

31 Florbela Espanca. Ricordo di Guido Battelli, Firenze, Il Cenacolo, 1950. 